\title{
Effect of pre-flaring and file size on the accuracy of two electronic apex locators
}

\author{
Manoel BRITO-JÚNIOR ${ }^{1}$, Carla Cristina CAMILO'ㄹ, Gil MOREIRA-JÚNIOR², Jesus Djalma PECORA ${ }^{3}$, Manoel Damião \\ SOUSA-NETO3

\begin{abstract}
1- DDS, MSc, PhD student, Inter-institutional PhD program, State University of Montes Claros, Montes Claros, MG, Brazil; Department of Restorative Dentistry, School of Dentistry, University of São Paulo, Ribeirão Preto, SP, Brazil.

2- DDS, MSc, PhD, Dental School, University of Itaúna, Itaúna, MG, Brazil.

3- DDS, MSc, PhD, Department of Restorative Dentistry, School of Dentistry, University of São Paulo, Ribeirão Preto, SP, Brazil.
\end{abstract}

Corresponding address: Manoel Brito Júnior - Av. Rui Braga s/n, Vila Mauricéia - 39401-089 - Montes Claros - MG - Brazil - Phone: (38) 3229-8284 - e-mail: manoelbritojr@gmail.com

Received: February 7, 2012 - Modification: April 9, 2012 - Accepted: August 23, 2012

\section{ABSTRACT}

\begin{abstract}
bjective: This ex vivo study evaluated the effect of pre-flaring and file size on the accuracy of the Root ZX and Novapex electronic apex locators (EALs). Material and methods: The actual working length (WL) was set $1 \mathrm{~mm}$ short of the apical foramen in the palatal root canals of 24 extracted maxillary molars. The teeth were embedded in an alginate mold, and two examiners performed the electronic measurements using \#10, \#15, and \#20 K-files. The files were inserted into the root canals until the "0.0" or "APEX" signals were observed on the LED or display screens for the Novapex and Root ZX, respectively, retracting to the 1.0 mark. The measurements were repeated after the preflaring using the S1 and SX Pro-Taper instruments. Two measurements were performed for each condition and the means were used. Intra-class correlation coefficients (ICCs) were calculated to verify the intra- and inter-examiner agreement. The mean differences between the WL and electronic length values were analyzed by the three-way ANOVA test $(p<0.05)$. Results: ICCs were high $(>0.8)$ and the results demonstrated a similar accuracy for both EALs $(p>0.05)$. Statistically significant accurate measurements were verified in the pre-flared canals, except for the Novapex using a \#20 K-file. Conclusions: The tested EALs showed acceptable accuracy, whereas the pre-flaring procedure revealed a more significant effect than the used file size .
\end{abstract}

Key words: Endodontics. Odontometry. Root canal preparation. Tooth apex.

\section{INTRODUCTION}

The correct determination of the working length is an essential step during endodontic therapy. Although the radiographic method plays an important role in achieving acceptable root canal measurements, electronic apex locators (EALs) have been widely used for this purpose as well ${ }^{14}$. Several studies ${ }^{19,30,34}$ compared the accuracy of different models of EALs with radiographic root canal length determination and showed that the electronic methods provided the best results. In addition, the EALs have the advantage of reducing the number of radiographs required to establish the apical limit of root canal instrumentation in clinical practice $^{11,23}$.
However, although the use of EALs is well established, predictable and reproducible electronic readings were only possible with the development of last generation devices ${ }^{14}$. Root ZX (J. Morita CO., Tokyo, Japan) and Novapex (Forum Engineering Technologies Ltd., Rishon Lezion, Israel) are commercially available modern EALs that measure the impedance between the file tip and the root canal at different frequencies ${ }^{8,14}$. These EALs present satisfactory performance in the presence of blood, fluids, or irrigating solutions $4,5,8,26,27$ as well as during retreatment procedures ${ }^{1,13}$. A high accuracy rate of measurements that are $0.5-1 \mathrm{~mm}$ closer to the actual length are possible using these devices ${ }^{8,26}$.

Several factors may influence the accuracy of 


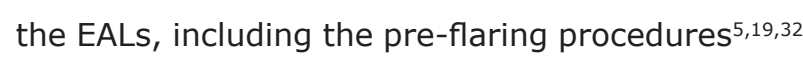
and the size of the measuring file related to the root

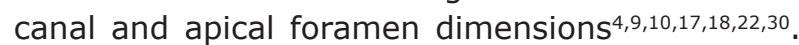
Files inserted in pre-flared canals can easily reach the apical constriction, presenting a lower incidence of overextension than those placed in un-flared canals $^{25}$. Moreover, some studies ${ }^{5,19}$ found that the pre-flaring procedure increased the accuracy of some EALs, although other authors ${ }^{32}$ reported divergent results. Measurements performed in the root canal with increasing diameters were inaccurate using small files ${ }^{10}$. Similar findings were observed when the apical constriction width had been increased ${ }^{9}$. On the contrary, other investigations verified that the accuracy of the electronic measurements do not depend on the file size utilized ${ }^{4,30}$, even when using small size files in enlarged root canals ${ }^{15,22}$. Recently, a critical apical foramen diameter of $0.8 \mathrm{~mm}$ was determined for an acceptable accuracy of the Root ZX using small size files ${ }^{17}$.

One reason that small size files can produce unstable and inaccurate measurements in wide canals is the exposition of a more metallic surface to the surrounding electrolyte ${ }^{30}$. These authors found an improved accuracy of some EALs using a \#15 file when compared with a \#10 file positioned directly at the major foramen. Large diameter files will fit more tightly, thus producing more accurate electronic measurements ${ }^{9}$. In this regard, pre-flaring facilitates a larger file size to reach the apical constriction, once it removes cervical dentin interferences ${ }^{31}$. Furthermore, this procedure establishes a more accurate relationship between the file size and anatomical foramen diameter ${ }^{25}$. However, limited information is available on the accuracy of EALs in wide root canals under both combined conditions (pre-flaring and file size).

The purpose of this ex vivo study was to evaluate the effect of pre-flaring and the size of the measuring file on the accuracy of the Root ZX and Novapex in the palatal root canals of extracted maxillary molars. The null hypothesis was that the accuracy of the two EALs will not be altered by the pre-flaring procedures or measuring file.

\section{MATERIAL AND METHODS}

The present study was approved by the Research Ethics Committee of the State University of Montes Claros (Protocol number 506/2006).

\section{Sample selection and preparation}

Twenty-four extracted maxillary molars were selected after a radiographic examination. The following criteria were used for the tooth selection: well-preserved coronal and radicular structures, fully formed apices, and similar root lengths.
Another criterion for selection was the accessibility of the apical foramen, with at least a \#06 K-file (Dentsply-Maillefer, Ballaigues, Switzerland) in the palatal root canals, which is the focus of the study. Exclusion criteria were the presence of metallic restorations and a root presenting resorption or fractures.

Coronal access to the teeth was initially performed with a \#1557 tapered carbide bur (S.S. White Dental products, Rio de Janeiro, RJ, Brazil) at high speed and refined with an Endo-Z bur (Dentsply-Maillefer). The occlusal surfaces of the molars were sectioned using a diamond disc (Isomet, Buehler, Evanstone, IL, USA) to expose a flat dentin surface. This procedure was performed to provide a stable and reproducible reference point for root canal measurements. The root apex was fixed in contact with a rigid plate to determine the actual work length. A \#10 K-file with a rubber stop was inserted in the canal and advanced until the file tip met the rigid plate. Thus, the file tip was flush with the apical foramen ${ }^{16}$. At this moment, the rubber stop was adjusted to the chosen reference point, the file was removed, and a millimeter ruler (DentsplyMaillefer) was used to measure the verified length. From this measurement, $1 \mathrm{~mm}$ was subtracted to achieve the actual work length.

\section{Electronic working length determination}

The electronic working length was obtained using Root ZX or Novapex EALs and \#10, \#15, or \#20 K-files (Dentsply-Malleifer). Thus, six experimental conditions were determined. An ex vivo experimental model based on a previous study $^{5}$ was used. The teeth were immersed in a plastic box containing fresh alginate (Jeltrate II; Dentsply, Petropolis, RJ, Brazil). Two orifices were performed, one localized in the center of the box to permit the placement of the teeth and the other laterally to insert the lip electrode of the EALs. Before determining the electronic length, the root canals were irrigated with $1 \%$ sodium hypochlorite $(\mathrm{NaOCl})$ solution. Excess from the pulp chamber was removed with cotton pellets. The lip electrode was inserted in the respective orifice in contact with the alginate and the experimental condition file under evaluation was connected to the other electrode for the electronic measurements. For each EAL used, the file was inserted into the root canal until the "0.0" or "APEX" signals were observed on the LED or display screens for the Novapex and Root $Z X$, respectively. The file was retracted until the LED or display showed the 1-mm mark. A rubber stop was then adjusted to the reference level, and the distance between the rubber stop and the file was measured with an endodontic ruler (DentsplyMaillefer).

Another factor evaluated was the effect 
of the pre-flaring procedure in the electronic measurements. Pre-flaring was performed by root canal enlargement from the cervical up to the middle third. An engine-driven instrument (X-Smart; Dentsply-Maillefer) with the S1 and SX ProTaper instruments (Dentsply-Maillefer) was used for this purpose. The S1 instrument was introduced into the canal until $3 \mathrm{~mm}$ from the previously determined working length. Afterward, the SX instrument was used with a brushing motion up to the middle third ${ }^{5}$. Irrigation with $2 \mathrm{~mL} 1 \% \mathrm{NaOCl}$ was performed after the use of each rotary instrument. Two measurements at three-week intervals were performed for each experimental condition, before and after the preflaring procedures by two examiners (specialists in endodontics). The experimental design is described in Figure 1.

Electronic measurements restricted to $1 \mathrm{~mm}$ short of the apical foramen or presenting $\pm 0.5 \mathrm{~mm}$ of error variation were classified as precise and acceptable, respectively. Mistaken measurements were higher or lower than the acceptable values ${ }^{5}$.

\section{Statistical analysis}

The mean of the measurements of each EAL was used for the statistical analysis. The accuracy was calculated only on the stable measurements. Intra-class correlation coefficients (ICC) were used to verify the intra- and inter-examiner agreement. The mean differences between the actual length and electronic length values were analyzed by three-way ANOVA test with a significance level of $5 \%$. The factors evaluated were "EALs", "size of file" and "presence of pre-flaring".

\section{RESULTS}

The ICCs were generally high, ranging from 0.872 to 0.964 (intra-examiner agreement) and 0.806 to 0.896 (inter-examiner agreement).

Figure 2 displays the relative frequency of
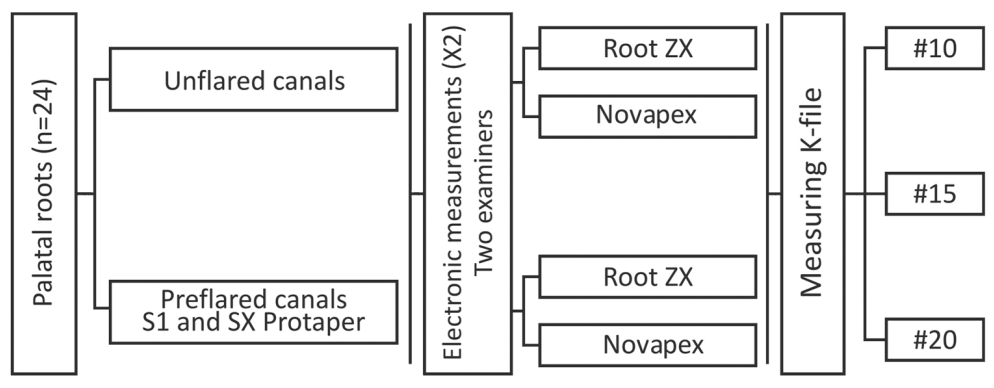

Figure 1- Experimental design

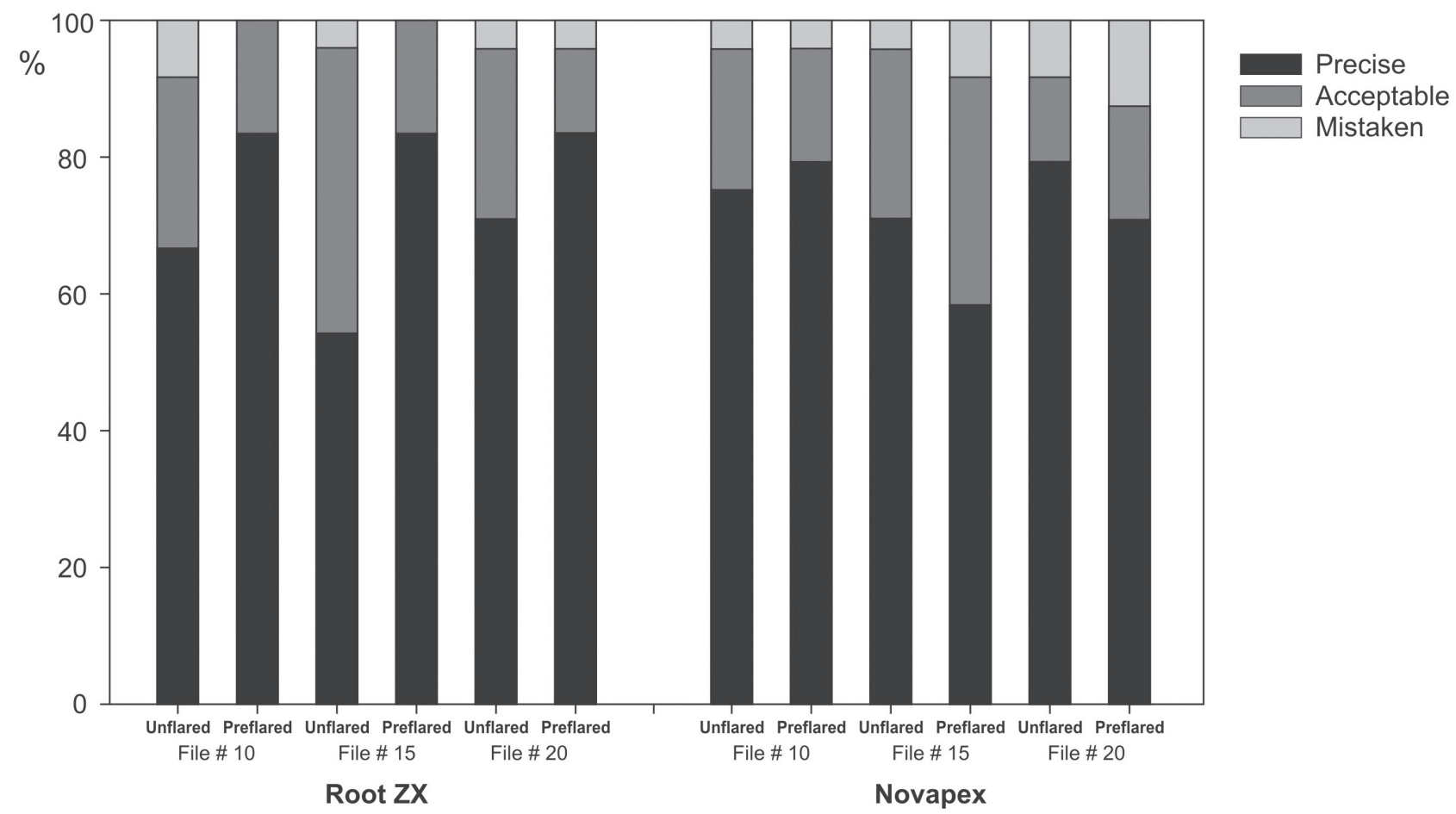

Figure 2- Relative frequency of precise, acceptable and mistaken measurements for each eletronic apex locator in unflared and pre-flared canals 


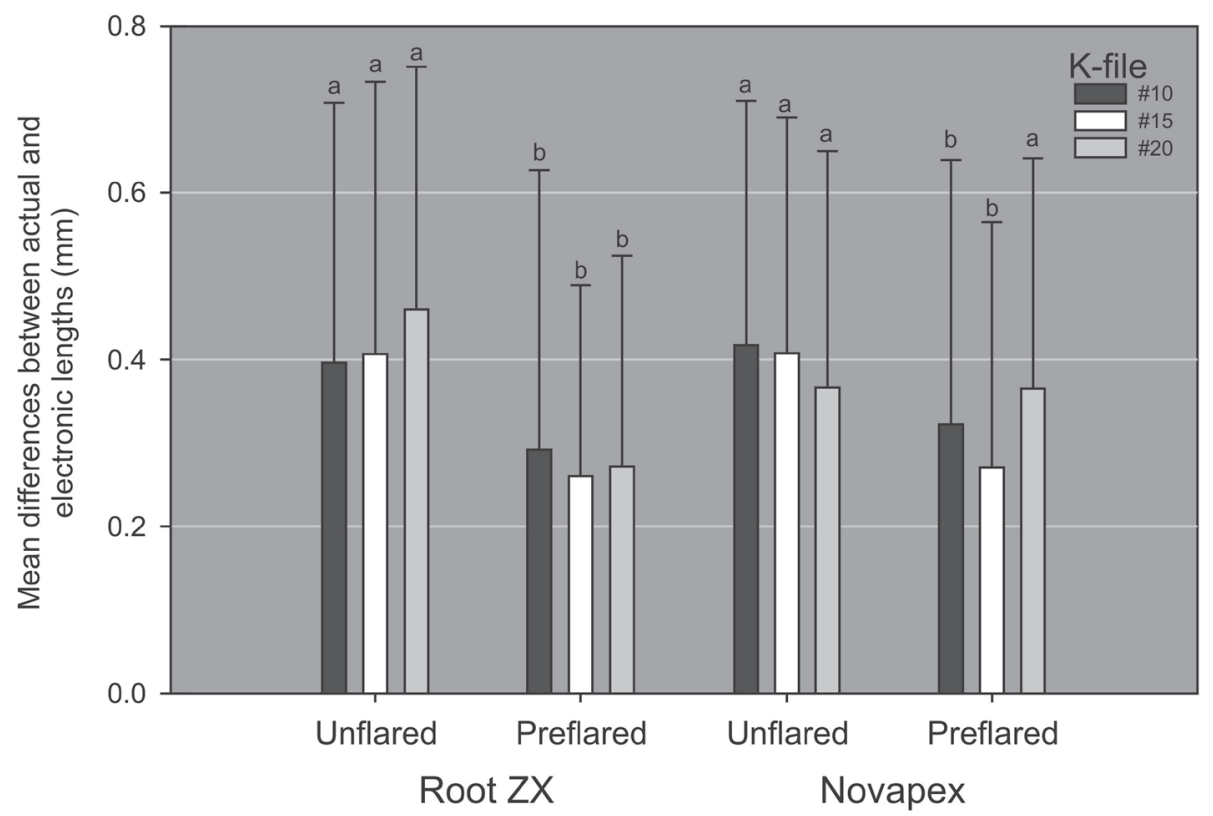

Figure 3- Mean differences (SD) between actual and electronic lengths according to the file size used in un-flared and pre-flared root canals. Different letters indicate significant differences $(p<0.05)$ between each file size in the Root $Z X$ and Novapex devices

precise, acceptable and mistaken measurements for each EAL in the experimental conditions.

No significant differences were observed in the accuracy of both EALs when compared with the actual lengths. The pre-flaring procedure significantly $(p<0.05)$ increased the accuracy of the measurements for the Root $Z X$, regardless of the file used. Similarly, the Novapex was more accurate after the pre-flaring, except with the \#20 K-file (Figure 3).

\section{DISCUSSION}

Due to continued dentine formation, the floor of the pulp chamber presents an increased thickness of dentine, resulting in a coronal constriction of the root canal space. The removal of this cervical interference by pre-flaring improved the accuracy of the work length and file size determination ${ }^{25,31}$. However, the pre-flaring of the root canals and measuring file characteristics are controversial topics related to the accuracy of the EALs. Considering these variables, the present study assessed the performance of the most widely investigated EAL, the Root-ZX, and a device that has received little attention in the literature, the Novapex. The results indicated that the pre-flaring procedure provided more accurate measurements in most cases. Conversely, the measurement file size has no significant impact on the accuracy of the measurements. Thus, the null hypothesis was rejected.

Ex vivo experimental methods for studying the accuracy of EALs often use electroconductive materials such as alginate, gelatine, agar, or saline media $2-7,12,26,30$. These embedding media may reproduce the impedance values of human tissues, thus simulating the clinical situation. However, some substances can leak through the apical foramen and cause premature readings ${ }^{2}$. Thus, protocols involving the use of alginate are reportedly more reliable and reproducible ${ }^{2,7,26}$. The relative stiffness, good electroconductive property, and gel consistency, which allow ions to circulate, are favorable characteristics of alginate that simulate the periodontal ligament ${ }^{2,26}$. For these reasons, the teeth were embedded in an alginate mold for electronic measurements in the present study.

Apical constriction is the generally accepted landmark of root canal instrumentation and obturation ${ }^{28}$. In this study, the length obtained via endodontic measurements was established as the gold standard. This working length has been determined under direct or microscopic visualization and subtracting $1 \mathrm{~mm}$ as soon as the measuring file was visible at the apical foramen"5. Thus, the " 0.0 " mark in the Novapex and the "APEX" of the RootZX displays with subsequent retracting to the 1.0 mark were used as an apical endpoint. Although the $1-\mathrm{mm}$ mark of the EALs in most of the cases does not correspond to a measurement of $1 \mathrm{~mm}$ from the apical foramen ${ }^{33}$, one study ${ }^{15}$ found that subtracting only $0.5 \mathrm{~mm}$ resulted in file overextension when some EALs were used. Moreover, other studies 3,5,20 showed a high accuracy rate using the 1-mm mark of the Root ZX and Novapex devices, corroborating with the present findings.

Different accuracy ranges have been considered 
to evaluate the EALs within $0.5 \mathrm{~mm}$ and 1 $\mathrm{mm}^{5,6,8,17,18,26,30}$. The Root $\mathrm{ZX}$ was able to measure the working length $( \pm 0.5 \mathrm{~mm})$ in more than $97 \%$ of the cases by taking the apical foramen as a landmark for the actual length ${ }^{5,26}$. In another similar study, accurate measurements $( \pm 0.5 \mathrm{~mm})$ were found in $89.7 \%$ and $82.1 \%$ of the cases using the Root ZX and Novapex, respectively ${ }^{8}$. Considering an error range of $1 \mathrm{~mm}$, the root canal length obtained using the Root ZX was accurate in $100 \%$ of the cases $^{26}$. The high accuracy rates verified in the present study for both EALs, regardless of the tested experimental condition, supports the results of the cited investigations. However, it was not possible to attain accurate measurements in all of the cases in this study, even when considering a tolerance of $\pm 1 \mathrm{~mm}$. In addition, no cases of overextension were observed, which is consistent with another ex vivo study ${ }^{18}$, although other authors ${ }^{8}$ have reported overestimated measurements in $7.6 \%$ and $12.8 \%$ of the cases for the Root ZX and Novapex, respectively. Additional research parameters, including tooth type and file sizes used, can explain the divergent findings of the last mentioned investigation and those of the present study.

The hypothesis that the use of a larger file size (e.g. \#20 K-file) could result in more suitable electronic length values in wide canals, such as the palatal root canals of the maxillary molars, was not confirmed. Other studies ${ }^{18,22}$ also verified that the size of the endodontic file does not need to be proportional to the size of the canal for predictability of the electronic measurements. This was demonstrated especially in apical root canal diameters smaller than $0.6 \mathrm{~mm}^{17,18}$. Considering that the anatomical dimension of the apical foramen in palatal canals is approximately $0.3 \mathrm{~mm}^{24}$, the results of this study concur with those previously described. Moreover, the wide range of apical diameters as well as the oval to flattened crosssections found in the palatal roots of human teeth can hinder even large size instruments to fit in the apical region ${ }^{24}$. Thus, such anatomical variations found between and within the palatal canals were possibly decisive factors for the similarity of the electronic measurements using different file sizes.

Nickel-titanium instruments like the ProTaper have been recommended for coronal pre-flaring, presenting a greater dentin cutting ability and safety during the preparation procedures ${ }^{29}$. In the present study, the use of the S1 and SX ProTaper instruments ensured a suitable enlargement of the cervical and middle thirds of the root canals, as previously verified ${ }^{5}$. Pre-flaring increased the efficiency of the Root ZX in the mandibular molars ${ }^{19}$ and incisor ${ }^{5}$ canals, corroborating with the present data obtained in the palatal root canals of the maxillary molars. The accurate readings were also superior in the pre-flared canals for the Novapex using \#10 and \#15 K-files. A recent study ${ }^{21}$ showed that the accuracy of the Novapex increased after the pre-flaring of the incisor mandibular canals, but there was no significant difference compared with the un-flared canals. Equivalent performances of the Novapex and Root ZX could be expected using a \#20 K-file in the pre-flared canals in the present study. However, this result was not confirmed, suggesting that the pre-flaring procedure associated with larger-sized files can produce different effects on the accuracy of the measurements, depending on the tested EAL. Further research will be developed to address this issue.

\section{CONCLUSION}

Within the limitations of this ex vivo study, it may be concluded that the Root ZX and Novapex EALs showed an acceptable accuracy in the palatal root canals of the maxillary molars. The cervical preflaring presented significantly increased accuracy in the electronic measurements that the file size used.

\section{REFERENCES}

1- Aggarwal V, Singla M, Kabi D. An in vitro evaluation of performance of two electronic root canal length measurement devices during retreatment of different obturating materials. J Endod. 2010;36:1526-30.

2- Baldi JV, Victorino FR, Bernardes RA, Moraes IG, Bramante CM, Garcia RB, et al. Influence of embedding media on the assessment of electronic apex locators. J Endod. 2007;33:476-9.

3- Bernardes RA, Duarte MA, Vasconcelos BC, Moraes IG, Bernardineli N, Garcia RB, et al. Evaluation of precision of length determination with 3 electronic apex locators: Root ZX, Elements Diagnostic Unit and Apex Locator, and RomiAPEX D-30. Oral Surg Oral Med Oral Pathol Oral Radiol Endod. 2007;104:e91-4.

4- Briseño-Marroquín B, Frajlich S, Goldberg F, Willershausen B. Influence of instrument size on the accuracy of different apex locators: an in vitro study. J Endod. 2008;34:698-702.

5- Camargo EJ, Zapata RO, Medeiros PL, Bramante CM, Bernardineli N, Garcia RB, et al. Influence of pre-flaring on the accuracy of length determination with four electronic apex locators. J Endod. 2009;35:1300-2.

6- Carvalho AL, Moura-Netto C, Moura AA, Marques MM, Davidowicz $\mathrm{H}$. Accuracy of three electronic apex locators in the presence of different irrigating solutions. Braz Oral Res. 2010;24:394-8.

7- Chen E, Kaing S, Mohan H, Ting SY, Wu J, Parashos P. An ex vivo comparison of electronic apex locator teaching models. J Endod. 2011;37:1147-51.

8- D'Assunção FL, Albuquerque DS, Queiroz Ferreira LC. The ability of two apex locators to locate the apical foramen: an in vitro study. J Endod. 2006,32:560-2.

9- Ebrahim AK, Wadachi R, Suda H. Ex vivo evaluation of the ability of four different electronic apex locators to determine the working length in teeth with various foramen diameters. Aust Dent J. 2006;51:258-62.

10- Ebrahim AK, Yoshioka T, Kobayashi C, Suda H. The effects of file size, sodium hypochlorite and blood on the accuracy of the Root ZX apex locator in enlarged root canals: an in vitro study. Aust Dent J. 2006;51:153-7.

11- Fouad AF, Reid LC. Effect of using electronic apex locators on selected endodontic treatment parameters. J Endod. 2000;26:3647. 
12- Genç Ö, Alaçam T, Kayaoglu G. Evaluation of three instrumentation techniques on the precision of the apical stop and apical sealing of obturation. J Appl Oral Sci. 2011;19:350-4. 13- Goldberg F, Marroquín BB, Frajlich S, Dreyer C. In vitro evaluation of the ability of three apex locators to determine the working length during retreatment. J Endod. 2005;31:676-8. 14- Gordon MP, Chandler NP. Electronic apex locators. Int Endod J. 2004;37:425-37.

15- Guise GM, Goodell GG, Imamura GM. In vitro comparison of three electronic apex locators. J Endod. 2010,36:279-81.

16- Heo MS, Han DH, An BM, Huh KH, Yi WJ, Lee SS, et al. Effect of ambient light and bit depth of digital radiograph on observer performance in determination of endodontic file positioning. Oral Surg Oral Med Oral Pathol Oral Radiol Endod. 2008;105:239-44. 17- Herrera M, Ábalos C, Lucena C, Jiménez-Planas A, Llamas R. Critical diameter of apical foramen and of file size using the Root ZX apex locator: an in vitro study. J Endod. 2011;37:1306-9. 18- Herrera M, Ábalos C, Planas AJ, Llamas R. Influence of apical constriction diameter on Root ZX apex locator precision. J Endod. 2007;33:995-8.

19- Ibarrola JL, Chapman BL, Howard JH, Knowles KI, Ludlow MO. Effect of pre-flaring on Root ZX apex locators. J Endod. 1999;25:625-6.

20- Mancini M, Felici R, Conte G, Costantini M, Cianconi L. Accuracy of three electronic apex locators in anterior and posterior teeth: an ex vivo study. J Endod. 2011;37:684-7.

21- Morgental RD, Vier-Pelisser FV, Luisi SB, Cogo DM, Kopper PMP. Pre-flaring effects on the accuracy of three electronic apex locators. Rev Odonto Ciênc. 2011;26:331-5.

22- Nguyen HQ, Kaufman AY, Komorowski RC, Friedman S. Electronic length measurement using small and large files in enlarged canals. Int Endod J. 1996;29:359-64.

23- Paludo L, Souza SL, Só MV, Rosa RA, Vier-Pelisser FV, Duarte $\mathrm{MA}$. An in vivo radiographic evaluation of the accuracy of Apex and iPex electronic Apex locators. Braz Dent J. 2012;23:54-8.

24- Paqué F, Zehnder M, Marending M. Apical fit of initial K-files in maxillary molars assessed by micro-computed tomography. Int Endod J. 2010;43:328-35.
25- Pecora JD, Capelli A, Guerisoli DM, Spanó JC, Estrela C. Influence of cervical pre-flaring on apical file size determination. Int Endod J. 2005;38:430-5.

26- Plotino G, Grande NM, Brigante L, Lesti B, Somma F. Ex vivo accuracy of three electronic apex locators: Root ZX, Elements Diagnostic Unit, Apex Locator and ProPex. Int Endod J. 2006;39:408-14.

27- Renner D, Grazziotin-Soares R, Gavini G, Barletta FB. Influence of pulp condition on the accuracy of an electronic foramen locator in posterior teeth: an in vivo study. Braz Oral Res. 2012;26:106-11. 28- Ricucci D, Langeland K. Apical limit of root canal instrumentation and obturation, part 2. A histological study. Int Endod J. 1998;31:394-409.

29- Sanfelice CM, Costa FB, Reis Só MV, Vier-Pelisser F, Souza Bier CA, Grecca FS. Effects of four instruments on coronal preenlargement by using cone beam computed tomography. J Endod. 2010;36:858-61.

30- Stoll R, Urban-Klein B, Roggendorf MJ, Jablonski-Momeni A, Strauch K, Frankenberger R. Effectiveness of four electronic apex locators to determine the distance from the apical foramen. Int Endod J. 2010;43:808-17.

31- Tennert C, Herbert J, Altenburger MJ, Wrbas KT. The effect of cervical pre-flaring using different rotary nickel-titanium systems on the accuracy of apical file size determination. J Endod. 2010;36:1669-72.

32- Tinaz AC, Maden M, Aydin C, Türköz E. The accuracy of three different electronic root canal measuring devices: an in vitro evaluation. J Oral Sci. 2002;44:91-5.

33- Vasconcelos BC, Vale TM, Menezes AS, Pinheiro-Junior EC, Vivacqua-Gomes N, Bernardes RA, et al. An ex vivo comparison of root canal length determination by three electronic apex locators at positions short of the apical foramen. Oral Surg Oral Med Oral Pathol Oral Radiol Endod. 2010;110:e57-61.

34- Vieyra JP, Acosta J. Comparison of working length determination with radiographs and four electronic apex locators. Int Endod J. 2011;44:510-8. 